\title{
Molecular characterization, tissue expression profile, and single nucleotide polymorphism analysis of the periostin gene in swine
}

\author{
D. Xu, H.M. Ma and D.F. Xiao \\ College of Animal Science and Technology, Hunan Agricultural University, \\ Changsha, Hunan, China \\ Corresponding authors: H.M. Ma / D.F. Xiao \\ E-mail: mahaiming2000@163.com / xiaodingfu2001@163.com \\ Genet. Mol. Res. 15 (1): gmr.15017187 \\ Received September 14, 2015 \\ Accepted November 13, 2015 \\ Published March 11, 2016 \\ DOI http://dx.doi.org/10.4238/gmr.15017187
}

ABSTRACT. Periostin, also called osteoblast-specific factor 2, is an important regulator of bone, cardiac development, and wound healing. A recent study revealed that periostin plays an important role in tumor development and is upregulated in a wide variety of cancers. However, little is known about periostin in swine. Therefore, the cDNA sequence of the porcine periostin gene was obtained by rapid amplification of cDNA ends (RACE). One $C / T$ single nucleotide polymorphism anchored in intron 9 was identified and genotyped by PCR-RFLP-HaellI. In Daweizi, Shaziling, Ningxiang, Taoyuan, Wuzhishan, Landrace, and Yorkshire pigs, the $C$ allele was dominant, while the $T$ allele was dominant in the Duroc pig. Quantitative PCR analysis showed that the periostin gene was expressed in all examined tissues from 25-day-old Shaziling and Yorkshire piglets, with mRNA expression in the longissimus dorsi muscle being the highest in these two breeds, and that in the kidney and lungs being the lowest. There was a significant difference in periostin gene expression in the 
intestines, heart, and spleen $(P<0.05)$. These findings might contribute to our understanding of the function of periostin in swine.

Key words: Pig; Periostin; Expression profile; SNP

\section{INTRODUCTION}

Periostin is an important extracellular matrix (ECM) protein belonging to the fasciclin family of proteins (Wang and Mao, 2007), which promotes the proliferation and migration of cells (Tsunoda et al., 2009). In the long-term overload of heart stimulation and myocardial infarction, periostin plays a key role in the development of cardiac hypertrophy, interstitial fibrosis, and ventricular remodeling (Norris et al., 2004), and is also involved in wound healing (Roy et al., 2007). Periostin is an important regulatory factor involved in the development and remodeling of bone, and following a fracture, the expression of periostin mRNA was found to increase 2-fold, and was associated with osteogenic precursor cells in periosteal and undifferentiated mesenchymal cells near the fracture site (Nakazawa et al., 2004). Periostin is also involved in the growth of endometrial blood vessels and the development of atherosclerosis (Bagnato et al., 2007). In addition, a relationship between the periostin gene and the presence and development of atherosclerosis has been found. In the rat carotid artery balloon injury model, the level of periostin mRNA and protein expression significantly increased in the damaged artery intima (Lindner et al., 2005). Furthermore, experiments have shown that periostin mRNA expression increased significantly in rat pulmonary artery smooth muscle cells under a hypoxic stress response, which is similar to the process that occurs during atherosclerosis ( $\mathrm{Li}$ et al., 2004). The results of other studies have shown that periostin can regulate breast cancer cells and the expression of kinase domain receptor in human capillary endothelial cells (Försti et al., 2007; Binion et al., 2008). Transforming growth factor-beta 1 (TGF$\beta 1$ ) was found to induce periostin production, and this finding has been confirmed in colon cancer cells (Tai et al., 2005). In addition to TGF- $\beta 1$, bone morphogenetic protein, platelet-derived growth factor (PDGF-aa, PDGF-bb), and fibroblast growth factor (FGF-B, FGF-A) were potential factors for star-shaped cells secreted periostin (Erkan et al., 2007). Fluorescence in situ hybridization has shown the periostin gene to be located on HSA13q13.3 in humans and on mouse chromosome 8A1.1-1.2 (Takeshita et al., 1993). Integrin-associated periostin can activate Akt/protein kinase B- and focal adhesion kinase-mediated signaling pathways, which increase cell survival and angiogenesis, invasion, metastasis, and importantly, epithelial to mesenchymal transition of carcinoma cells (Morra and Moch, 2011). The periostin gene is expressed abundantly in human and mouse, but no study has investigated its effect on meat quality in pigs. In this study, the cDNA sequence of the periostin gene was cloned by rapid amplification of cDNA ends (RACE) using tissue samples from pigs, and expression profiling of periostin mRNA in different tissues from different breeds was studied using quantitative PCR (q-PCR). This investigation aimed to lay a foundation for the further study of periostin in swine.

\section{MATERIAL AND METHODS}

\section{Generation of cDNA}

Total RNA was isolated using TRIzol reagent (Invitrogen, Karlsruhe, Germany) from the longissimus dorsi muscle of 25-day-old Yorkshire pigs (Zhang et al., 2010). RNA was treated with 
DNase I (Liang and Pardee, 1992) and then reverse-transcribed with Moloney Murine Leukemia Virus reverse transcriptase (Promega, Madison, WI, USA). The human periostin gene sequence (NM_001286667) was applied and compared with all sequences in the expressed sequence tags (EST) database using a standard BLAST (http://www.ncbi.nlm.nih/gov/blast/), and the porcine ESTs that shared at least $80 \%$ identity to the corresponding human mRNA were selected and used to design gene specific primers (Table 1). The PCR products were purified with the 3S Spin DNAAgarose Gel Purification system (Shenergy Biocolor, Shanghai, China) and cloned into the pMD18-T vector (TakaRa, Dalian, China), then sequenced by Shanghai Biosune Co. Ltd. (Shanghai, China).

Table 1. Sequences of primers used to perform PCR amplifications.

\begin{tabular}{|c|c|c|c|c|}
\hline Primers purpose & Primer name & Primer sequence $\left(5^{\prime}-3^{\prime}\right)$ & $\operatorname{Tm}\left({ }^{\circ} \mathrm{C}\right)$ & Product size $(\mathrm{bp})$ \\
\hline \multirow[t]{4}{*}{ Cloning } & RC11-1F & GAAGAACCCAGATTTTGTCAGC & \multirow[t]{2}{*}{55} & \multirow[t]{2}{*}{817} \\
\hline & RC11-1R & СTCTACTTCCCAAAAGGTCTCC & & \\
\hline & RC11-2F & CAGTGCTTCTCCCTGACCGA & \multirow[t]{2}{*}{55} & \multirow[t]{2}{*}{733} \\
\hline & RC11-2R & CTTTATTTTCCCATAGTTTTAGGTCAGA & & \\
\hline \multirow[t]{2}{*}{ Polymorphism } & Genomic-F & AGGAGCACTTATTCTTGT & \multirow[t]{2}{*}{59} & \multirow[t]{2}{*}{1249} \\
\hline & Genomic-R & AAATGCGTTATTCACAGG & & \\
\hline \multirow[t]{2}{*}{ Expression profile } & Periostin-F & AGCAAACCACTTTCACAGACCT & \multirow[t]{2}{*}{58} & \multirow[t]{2}{*}{101} \\
\hline & Periostin-R & AAATGCGTTATTCACAGGCG & & \\
\hline \multirow[t]{2}{*}{ Internal control } & GAPDH-F & ATTTGGCTACAGCAACAGGGT & \multirow[t]{2}{*}{59} & \multirow[t]{2}{*}{172} \\
\hline & GAPDH-R & AAGTCAGGAGATGCTCGGTGT & & \\
\hline
\end{tabular}

\section{SNP identification and PCR-RFLP test}

Blood samples were collected from the ears of eight swine breeds, including Duroc pigs $(\mathrm{N}=57)$, Landrace pigs $(\mathrm{N}=38)$, Yorkshire pigs $(\mathrm{N}=360)$, Shaziling pigs $(\mathrm{N}=63)$, Daweizi pigs $(\mathrm{N}$ = 62), Taoyuan pigs $(\mathrm{N}=70)$, Ningxiang pigs $(\mathrm{N}=77)$, and Wuzhishan pigs $(\mathrm{N}=55)$, and genomic DNAs were amplified and sequenced directly for the identification of single nucleotide polymorphisms (SNPs). The PCR for genotyping was performed in a volume of $20 \mu \mathrm{L}$ consisting of $100 \mathrm{ng}$ genomic DNA, 10X buffer, $0.5 \mu \mathrm{M}$ each primer, $75 \mu \mathrm{M}$ each dNTP, $1.5 \mathrm{mM} \mathrm{MgCl}$, and $0.5 \mathrm{U}$ Taq DNA polymerase (Promega). The PCR protocols were 5 min at $94^{\circ} \mathrm{C}$, followed by 35 cycles of 30 $\mathrm{s}$ at $94^{\circ} \mathrm{C}, 30 \mathrm{~s}$ at $50.5^{\circ} \mathrm{C}, 1 \mathrm{~min}$ at $72^{\circ} \mathrm{C}$, and a final extension of $10 \mathrm{~min}$ at $72^{\circ} \mathrm{C}$. A total of $4 \mu \mathrm{L}$ PCR product was digested overnight with $3 \cup$ Haelll (Thermo Fisher Scientific, USA) at $37^{\circ} \mathrm{C}$, then size-separated on $2.0 \%$ agarose gel stained with ethidium bromide.

\section{Expression profile of periostin gene}

Total RNA was isolated from 10 tissues (heart, liver, spleen, lung, kidney, intestine, cecum, pancreas, crureus, and longissimus dorsi muscle) of a 25-day-old weaned Yorkshire piglet and a Shaziling piglet of the same age (Winer et al., 1999; Zhang et al., 2010). The glyceraldehyde3-phosphate dehydrogenase (GAPDH) gene was used as an internal control. The expression profile and internal control primers were designed according to the pig mRNA sequence. Analysis of relative gene expression was conducted using real-time qPCR and the $2^{-\Delta \Delta C t}$ method (Livak and Schmittgen, 2001). 


\section{RESULTS}

\section{cDNA sequence}

Cloning and characterization of the porcine periostin cDNA sequence was performed using the RACE method, and the full-length cDNA was 2952 bp. It contained an open reading frame (ORF) of 2346 bp, a 5'-untranslated region (UTR) of 118 bp, and a 3'- UTR of 488 bp, encoding 781 amino acids. This gene was deposited to GenBank under the accession No. KF500034.

Periostin cDNAs from 12 species obtained from the NCBI database were used for phylogenetic tree analysis, including Pan troglodytes (XM_001148381.3), Mus musculus (NM_015784.3), Oryzias latipes (NM_001305404.1), Rattus norvegicus (NM_001108550.1), Canis lupus familiaris (LC019996), Homo sapiens (NM_006475.2), Bos taurus (NM_001040479.1), Aotus nancymaae (XM_012469826.1), Aquila chrysaetos canadensis (XM_011580807.1), Ovis aries musimon (XM_012130755.1), and Macaca nemestrina (XM_011748726.1). The results showed that the periostin cDNA sequences from different animals formed one subgroup. The highest homology was found between sheep and cattle sequences, and the lowest homology was with Oryzias latipes (Figure 1).

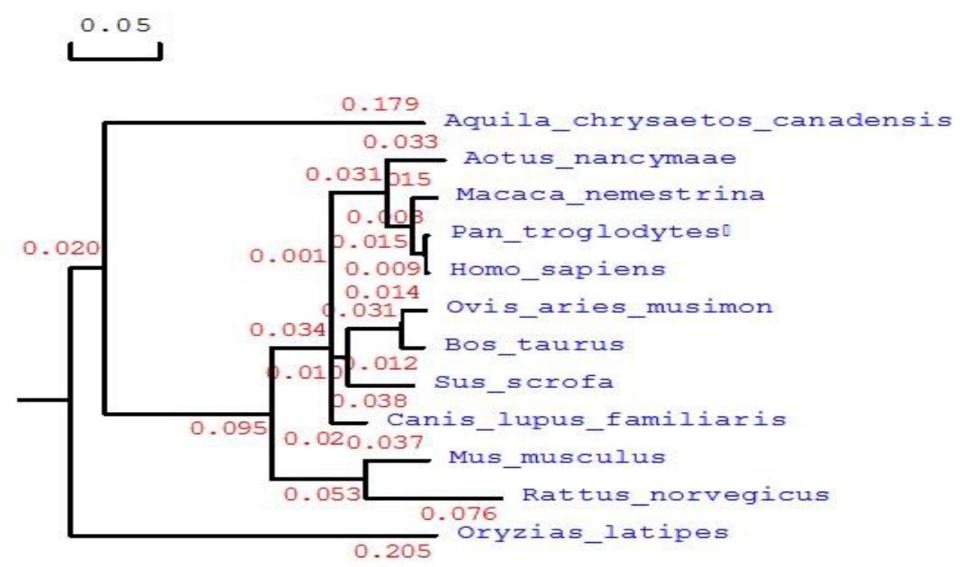

Figure 1. Phylogenetic tree of the cDNA sequences of periostin. The tree was constructed using the multiple-sequence alignment method in the DNAMAN 6.0 software.

\section{Polymorphism detection}

One SNP anchored in intron 9 of the periostin gene was identified. A genomic fragment of 1249 bp was amplified and subsequently genotyped with PCR-RFLP-Haelll (1249 bp for allele $T$, and 708 and $541 \mathrm{bp}$ for allele $C$ ) (Figure 2).

The gene and genotype frequencies were calculated for the eight pig breeds and independence tests of the periostin gene were conducted (Table 2). The chi-square test showed that there were significant differences between genotypes in the different breeds $(P<0.05)$. In Taoyuan and Wuzhishan pigs, the genotype frequencies were not significantly different $(P>0.05)$. Phenotype values of pigs carrying the TT genotype were significantly lower than those carrying the CC genotype $(P<0.05$; Table 2$)$. Allele $C$ was predominant in these pig breeds, except for in Duroc pig (Table 2), the highest $C$ gene frequency was 0.9921 in the native breed, Shaziling pig, the $T$ gene frequency was 0.7097 in the European breed Duroc pig, and the $T$ allele was not found in 
the Taoyuan and Wuzhishan pig breeds. From the genotype frequency distribution, CC was the dominant genotype.

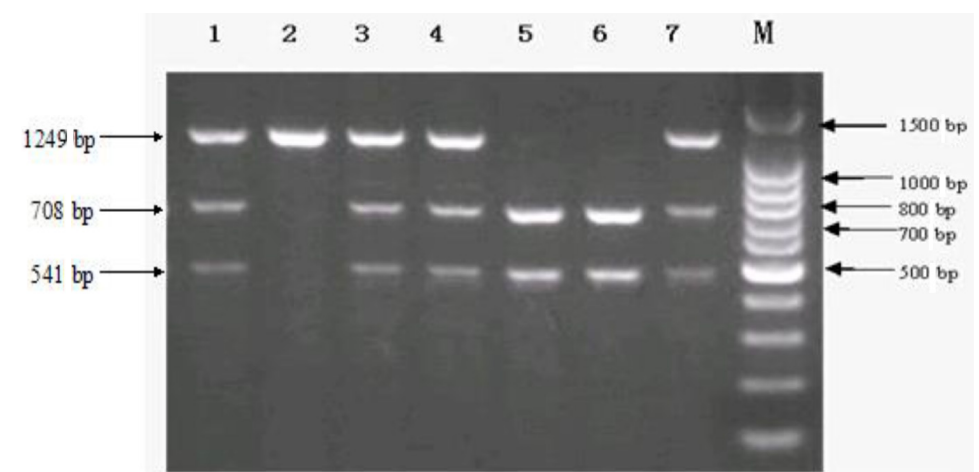

Figure 2. One single nucleotide polymorphism (SNP) was detected in the periostin gene. Polymerase chain reaction (PCR) products were digested with Haelll to distinguish different alleles. Agarose gel (2\%): lanes 1-7: TT genotype: lane 2, CC genotype: lanes 5 and 6, CT genotype: lanes 1, 3, 4, and 7. Lane M = DL100-bp DNA ladder.

Table 2. Frequency of alleles and genotypes of the periostin gene determined by PCR-RFLP-Haelll among different pig breeds.

\begin{tabular}{|c|c|c|c|c|c|c|c|c|c|c|}
\hline \multirow{2}{*}{ Breed } & \multirow{2}{*}{ Sample size } & \multicolumn{3}{|c|}{ Genotype } & \multicolumn{3}{|c|}{ Frequency of genotype } & \multicolumn{2}{|c|}{ Frequency of allele } & \multirow{2}{*}{$\chi^{2}$} \\
\hline & & $T T$ & $C T$ & $C C$ & $T T$ & $C T$ & $C C$ & $T$ & $C$ & \\
\hline Ningxiang & 77 & 0 & 31 & 46 & 0 & 0.5974 & 0.4026 & 0.2013 & 0.7987 & 4.8911 \\
\hline Daweizi & 62 & 0 & 3 & 59 & 0 & 0.0484 & 0.9516 & 0.0242 & 0.9758 & 0.0381 \\
\hline Shaziling & 63 & 0 & 1 & 62 & 0 & 0.0159 & 0.9841 & 0.0079 & 0.9921 & 0.0040 \\
\hline Taoyuan & 70 & 0 & 0 & 70 & 0 & 0 & 1 & 0 & 1 & - \\
\hline Wuzhishan & 55 & 0 & 0 & 55 & 0 & 0 & 1 & 0 & 1 & - \\
\hline Yorkshire & 360 & 44 & 145 & 171 & 0.1222 & 0.4028 & 0.475 & 0.3236 & 0.6764 & 2.3006 \\
\hline Landrace & 38 & 0 & 21 & 17 & 0 & 0.5526 & 0.4474 & 0.2763 & 0.7237 & 5.5398 \\
\hline Duroc & 62 & 35 & 18 & 9 & 0.5645 & 0.2903 & 0.1452 & 0.7097 & 0.2903 & 5.4122 \\
\hline
\end{tabular}

\section{Expression profile analysis}

RT-PCR was used to investigate the levels of periostin mRNA from the total RNA extracted from different tissues (heart, liver, spleen, lung, kidney, intestine, cecum, pancreas, crureus, and longissimus dorsi muscle). Quantitative PCR showed that the porcine periostin gene is broadly expressed in the 10 tissues examined from Yorkshire and Shaziling pigs (Figure 3). The housekeeping gene GAPDH was used as an endogenous reference for the determination of target mRNA expression, and the expression calibrator was set as 10 in spleen tissue from Shaziling pig for subsequent relative quantification of periostin mRNA levels. Periostin mRNA showed the highest expression in the longissimus dorsi muscle and almost no expression was found in the kidney and lungs from these two breeds $(P<0.01)$. The expression in the heart and spleen of Yorkshire pigs was higher than that in Shaziling pig $(P<0.05)$, and lower in the intestine $(P<0.05)$. 


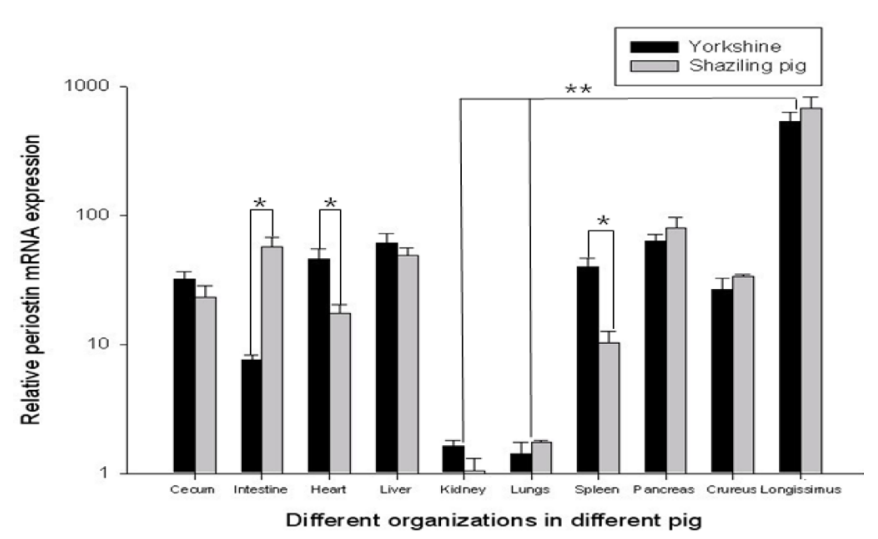

Figure 3. Comparison of the expression profiles of periostin mRNA in different tissues from 25-day-old Yorkshire and Shaziling pigs. ${ }^{*}$ Indicates $\mathrm{P}<0.05$, ${ }^{* *}$ Indicates $\mathrm{P}<0.01$.

\section{DISCUSSION}

Periostin, which was originally identified in a mouse (M. musculus) osteoblast cell line, has a molecular weight of $90 \mathrm{kDa}$, consists of 22 exons, 21 introns, and 811 amino acids, and is an ECM protein that is secreted by cardiac fibroblasts. The mouse periostin gene was located on chromosome 3.3C (Takeshita et al., 1993). The human (H. sapiens) periostin gene was located on chromosome 13q13.3, and contains 22 exons and 21 introns, encodes 761 amino acids, and is an important candidate gene for cardiovascular disease. Periostin contains an $\mathrm{N}$-terminal signal peptide, a cysteine-rich region, four internal homologous repeat sequences, and a C-terminal hydrophilic zone. Periostin is secreted by stromal-specific cells, and is mainly distributed in the ECM where it directly interacts with a variety of ECM proteins such as collagen I and IV, and fibronectin, to maintain the stability of the ECM environment (Snider et al., 2008). The N-terminal signal peptide sequence and four internal homologous repeat sequences mediate the association of periostin with integrins in the cell membrane, which mediate cell-to-cell and ECM adhesion (Litvin et al., 2005). Periostin also plays an important role in the repair of ECM (Suzuki et al., 2004), formation of the cytoskeleton, differentiation of fibroblasts (Snider et al., 2008), and the pathological and physiological processes of bone matrix remodeling. Although we found that the periostin gene was located on chromosome 11 in pigs (Ma et al., 2005), no further studies investigating the periostin gene in pigs have been reported. In this study, we performed RACE-PCR and finally obtained a 2952-bp full-length cDNA sequence, with a 2346-bp ORF flanked by a 118-bp 5'-UTR and a 488-bp 3'-UTR, encoding 781 amino acids. The cDNA sequences shared 92 and $86 \%$ identity with the human (GenBank accession No. NM_001286667) and mouse (GenBank accession No. NM_015784.3) gene sequences, respectively, and the encoded amino acid sequences shared 89 and $88 \%$ identify, respectively, indicating that the periostin gene is highly conserved in mammals.

Our results indicate that allele $C$ was dominant in all pig breeds studied except for Duroc pigs. The TT allele was not detected in the native pig breeds or in Landrace pigs, and the $T$ allele was not detected in the Taoyuan and Wuzhishan pigs. This result could be due to long-term directional selection, and the sample size should be expanded for further study. The chi-square test showed that genotypes differed significantly between different breeds $(P<0.05)$. In Taoyuan and Wuzhishan pigs, the genotype frequencies showed no significant difference $(P>0.05)$; however, 
highly significant differences exist between these two breeds and Duroc pigs $(P<0.05)$. The differences of the interaction were not significant in the remaining species studied $(P>0.05)$. The site was located in the conserved region of periostin genes, it is likely that the mutation observed within the conserved region had an impact on gene function. Therefore, the differences in periostin genotype frequencies in different varieties suggest that the site C12835T may have an impact on related traits.

In this study, C12835T on intron 9 of the periostin gene did not cause an amino acid change, but it could regulate the expression of amino acids in downstream exons. Whether the mutation affected mRNA expression, growth, or development remains to be determined. In living cells, the transcription of functional genes and protein translation ensures homeostasis of biochemical reactions, and overexpression of proteins could enable the transcription and translation of upstream mRNA encoding genes as part of negative feedback regulation. Periostin protein function in organisms, the expression levels of periostin mRNA and protein levels in relationships, and mutual adjustment mechanisms remain to be studied. To gain a better understanding of the role of periostin in pigs before the early stages of the growth and development, we examined the mRNA expression of periostin in 10 tissues from Shaziling and Yorkshire piglets. Differences in periostin mRNA expression between the two pig breeds showed that expression in longissimus dorsi muscle tissues was higher than in other tissues, and almost no expression was observed in the kidney and lungs. Muscle tissue is composed of muscle fibers, and, according to the oxidation characteristics, muscle fibers can be classified into slow-oxidative (type I), fast-oxidative (type Ila), fast-glycolytic (type Ilb), and intermediate (type IIx) fibers (Bottinelli and Reggiani, 2000). Early growth stages in animals are important for the metabolism of muscle fiber and conversion of contraction type (Yang et al., 2008). At 3-20 days old, the proportions of MyHC type I, type Ila, type IIx, and type IIb fibers were significantly changed in longissimus dorsi muscle, in which type I, type Ila, and type IIx fibers were significantly reduced, while type Ilb fibers were significantly increased (Xiaojing et al., 2005). The high expression of periostin in the longissimus dorsi muscle may be associated with the formation of muscle fibers in pig. Highly significant differences in expression between the kidney, lung, and longissimus dorsi muscle tissues were found by the chi-square test $(P<0.01)$, and there was no significant difference between the expression in the rest of the tissues $(P>0.05)$. Periostin mRNA was highly expressed in the heart, intestine, and spleen $(P<0.05)$. The mRNA levels of periostin in crureus and longissimus dorsi muscle tissues from Shaziling piglets were higher than from those in Yorkshire piglets at 25 days old, which may be related to its fine meat quality.

In summary, the full-length cDNA of the pig periostin gene was isolated and characterized, and one $C / T$ SNP, which relates to meat quality traits, was identified in intron 9 of the periostin gene. The spatial and temporal expression profiles of pig periostin mRNA showed abundant expression in longissimus dorsi muscle tissue, and different expression patterns were observed between two breeds with genetically distinctive backgrounds.

\section{Conflicts of interest}

The authors declare no conflict of interest.

\section{ACKNOWLEDGMENTS}

Research supported by the National High Technology Research and Development Program of China (\#2011AA100304), the National Excellent Doctoral Dissertation of Program of China (\#200972), the Natural Science Foundation of Hunan Province (\#13JJ1021), and the Key Program of Education Department of Hunan Province (\#12A060). 


\section{REFERENCES}

Bagnato C, Thumar J, Mayya V, Hwang SI, et al. (2007). Proteomics analysis of human coronary atherosclerotic plaque: a feasibility study of direct tissue proteomics by liquid chromatography and tandem mass spectrometry. Mol. Cell. Proteomics 6: 1088-1102. http://dx.doi.org/10.1074/mcp.M600259-MCP200

Binion DG, Otterson MF and Rafiee P (2008). Curcumin inhibits VEGF-mediated angiogenesis in human intestinal microvascular endothelial cells through COX-2 and MAPK inhibition. Gut 57: 1509-1517. http://dx.doi.org/10.1136/gut.2008.152496

Bottinelli R and Reggiani C (2000). Human skeletal muscle fibres: molecular and functional diversity. Prog. Biophys. Mol. Biol. 73: 195-262. http://dx.doi.org/10.1016/S0079-6107(00)00006-7

Erkan M, Kleeff J, Gorbachevski A, Reiser C, et al. (2007). Periostin creates a tumor-supportive microenvironment in the pancreas by sustaining fibrogenic stellate cell activity. Gastroenterology 132: 1447-1464. http://dx.doi.org/10.1053/j. gastro.2007.01.031

Försti A, Jin Q, Altieri A, Johansson R, et al. (2007). Polymorphisms in the KDR and POSTN genes: association with breast cancer susceptibility and prognosis. Breast Cancer Res. Treat. 101: 83-93. http://dx.doi.org/10.1007/s10549-006-9265-1

Li P, Oparil S, Feng W and Chen YF (2004). Hypoxia-responsive growth factors upregulate periostin and osteopontin expression via distinct signaling pathways in rat pulmonary arterial smooth muscle cells. J. Appl. Physiol. 97: 1550-1558, discussion 1549. http://dx.doi.org/10.1152/japplphysiol.01311.2003

Liang P and Pardee AB (1992). Differential display of eukaryotic messenger RNA by means of the polymerase chain reaction. Science 257: 967-971. http://dx.doi.org/10.1126/science.1354393

Lindner V, Wang Q, Conley BA, Friesel RE, et al. (2005). Vascular injury induces expression of periostin: implications for vascular cell differentiation and migration. Arterioscler. Thromb. Vasc. Biol. 25: 77-83.

Litvin J, Zhu S, Norris R and Markwald R (2005). Periostin family of proteins: therapeutic targets for heart disease. Anat. Rec. A Discov. Mol. Cell. Evol. Biol. 287A: 1205-1212. http://dx.doi.org/10.1002/ar.a.20237

Livak KJ and Schmittgen TD (2001). Analysis of relative gene expression data using real-time quantitative PCR and the 2(-Delta Delta C(T)) method. Methods 25: 402-408. http://dx.doi.org/10.1006/meth.2001.1262

$\mathrm{Ma} \mathrm{H}$, Liu X, Shi Q, He C, et al. (2005). Assignments of the GAS6, POSTN and EFNB2 genes to SSC11 by somatic cell and radiation hybrid panels. Anim. Genet. 36: 523-524.

Morra $\mathrm{L}$ and Moch $\mathrm{H}$ (2011). Periostin expression and epithelial-mesenchymal transition in cancer: a review and an update. Virchows Arch. 459: 465-475. http://dx.doi.org/10.1007/s00428-011-1151-5

Nakazawa T, Nakajima A, Seki N, Okawa A, et al. (2004). Gene expression of periostin in the early stage of fracture healing detected by cDNA microarray analysis. J. Orthop. Res. 22: 520-525. http://dx.doi.org/10.1016/j.orthres.2003.10.007

Norris RA, Kern CB, Wessels A, Moralez El, et al. (2004). Identification and detection of the periostin gene in cardiac development. Anat. Rec. A Discov. Mol. Cell. Evol. Biol. 281A: 1227-1233. http://dx.doi.org/10.1002/ar.a.20135

Roy S, Patel D, Khanna S, Gordillo GM, et al. (2007). Transcriptome-wide analysis of blood vessels laser captured from human skin and chronic wound-edge tissue. Proc. Natl. Acad. Sci. USA 104: 14472-14477. http://dx.doi.org/10.1073/ pnas. 0706793104

Snider P, Hinton RB, Moreno-Rodriguez RA, Wang J, et al. (2008). Periostin is required for maturation and extracellular matrix stabilization of noncardiomyocyte lineages of the heart. Circ. Res. 102: 752-760. http://dx.doi.org/10.1161/ CIRCRESAHA.107.159517

Suzuki H, Amizuka N, Kii I, Kawano Y, et al. (2004). Immunohistochemical localization of periostin in tooth and its surrounding tissues in mouse mandibles during development. Anat. Rec. A Discov. Mol. Cell. Evol. Biol. 281A: 1264-1275. http:/l dx.doi.org/10.1002/ar.a.20080

Tai IT, Dai M and Chen LB (2005). Periostin induction in tumor cell line explants and inhibition of in vitro cell growth by antiperiostin antibodies. Carcinogenesis 26: 908-915. http://dx.doi.org/10.1093/carcin/bgi034

Takeshita S, Kikuno R, Tezuka K and Amann E (1993). Osteoblast-specific factor 2: cloning of a putative bone adhesion protein with homology with the insect protein fasciclin I. Biochem. J. 294: 271-278. http://dx.doi.org/10.1042/bj2940271

Tsunoda T, Furusato B, Takashima Y, Ravulapalli S, et al. (2009). The increased expression of periostin during early stages of prostate cancer and advanced stages of cancer stroma. Prostate 69: 1398-1403. http://dx.doi.org/10.1002/pros.20988

Wang YD and Mao JW (2007). Expression of matrix metalloproteinase-1 and tumor necrosis factor-alpha in ulcerative colitis. World J. Gastroenterol. 13: 5926-5932. http://dx.doi.org/10.3748/wjg.v13.i44.5926

Winer J, Jung CK, Shackel I and Williams PM (1999). Development and validation of real-time quantitative reverse transcriptasepolymerase chain reaction for monitoring gene expression in cardiac myocytes in vitro. Anal. Biochem. 270: 41-49. http:// dx.doi.org/10.1006/abio.1999.4085

Xiaojing Y, Ruqian Z and Jie C (2005). The developmental changes of myofibre types in LD muscle of erhualian and large white pigs. Chin. J. Vet. Sci. Jan. 25: 89-93. 
Yang F, Chen DW, Huang JX and Liu ZH (2008). Developmental changes of myofiber types in longissimus dorsi muscle of Rongchang and DLY pigs under different nutrient condition. Acta Vet. Zootech. Sin. 39: 1701-1708.

Zhang D, Du Q, Xu B, Zhang Z, et al. (2010). The actin multigene family in Populus: organization, expression and phylogenetic analysis. Mol. Genet. Genomics 284: 105-119. http://dx.doi.org/10.1007/s00438-010-0552-5 